\title{
Viñetas COVID
}

\author{
COVID cartoons
}

\author{
Oscar G. Pamo-Reyna ${ }^{1}$
}

\begin{abstract}
Resumen
El autor presenta una serie de viñetas relativas a la pandemia COVID, desde marzo del 2020 hasta agosto del presente año. Esta serie de viñetas es una selección de aquellas que estuvieron circulando en las redes sociales (WhatsApp, Facebook), periódicos y revistas, locales y extranjeras. Cada una de ellas habla por sí sola y detrás hay una historia que el interesado puede recordar o indagar en los medios apropiados.
\end{abstract}

Palabras claves: viñetas, humorismo, pandemia, COVID-19.

\begin{abstract}
The author presents a series of comic vignettes relating to the COVID pandemic, from March 2020 to August of this year. This series of vignettes is a selection of those that were circulating on social networks (WhatsApp, Facebook), newspapers and magazines, local and foreign. Each of them speaks for itself and behind it there is a story that the interested person can remember or investigate in the appropriate means.
\end{abstract}

Keywords: cartoon, humor, pandemic, COVID-19.

Durante la actual pandemia de COVID-19, una de las formas de paliar la tensión ha sido recurrir al humor. Una de ellas ha sido el humorismo gráfico vertido en viñetas publicadas en periódicos y revistas que han circulado como memes en las principales redes sociales, léase, WhatsApp y Facebook, y en los periódicos.

1 Médico internista. Profesor principal, Facultad de Medicina, Universidad Peruana Cayetano Heredia, Lima, Perú
La presente es una selección de viñetas que han tratado diversos aspectos que hemos vivido, en tiempo real, durante la pandemia de COVID-19 desde marzo del 2020 hasta el presente. Como toda selección, esta es arbitraria en el sentido que el autor ha escogido aquellas que cumplen con el objetivo de esta presentación. Una limitante ha sido la imposibilidad de cubrir todas las publicaciones nacionales y extranjeras, por lo que, debo admitir, que la selección fue hecha con aquellas viñetas a las que tuve acceso o me fueron enviadas a través de las redes sociales.

Las viñetas son reproducidas tal como fueron difundidas, manteniéndose la autoría cuando ella consta. Por razones obvias, de circulación en las redes sociales, no siempre fue posible identificar las fuentes, aunque algunas son fácilmente identificables por el estilo del creador de la viñeta. La secuencia sigue una lógica temporal conforme se fue desarrollando la pandemia en nuestro país, y en el mundo también. Aunque las viñetas hablan por sí solas, detrás de cada una de ellas hay una historia que, fácilmente, se puede recordar o, para el futuro, buscar en los archivos correspondientes. 

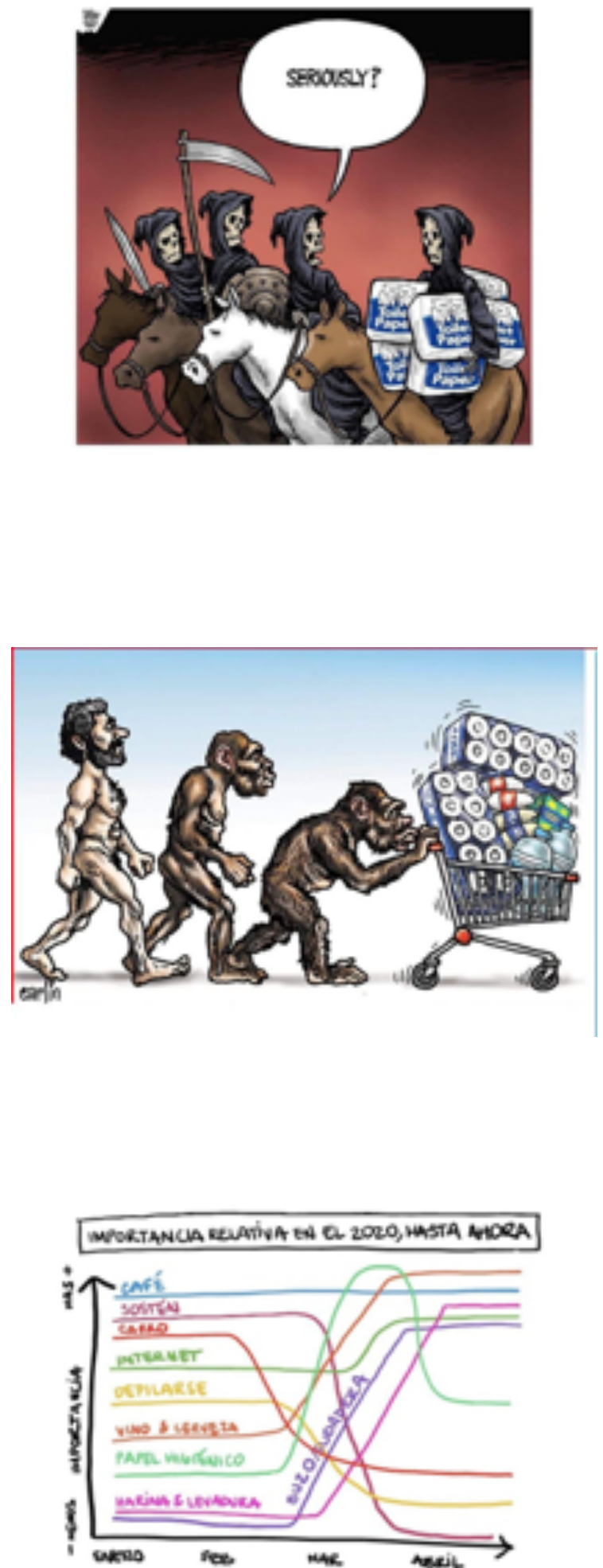
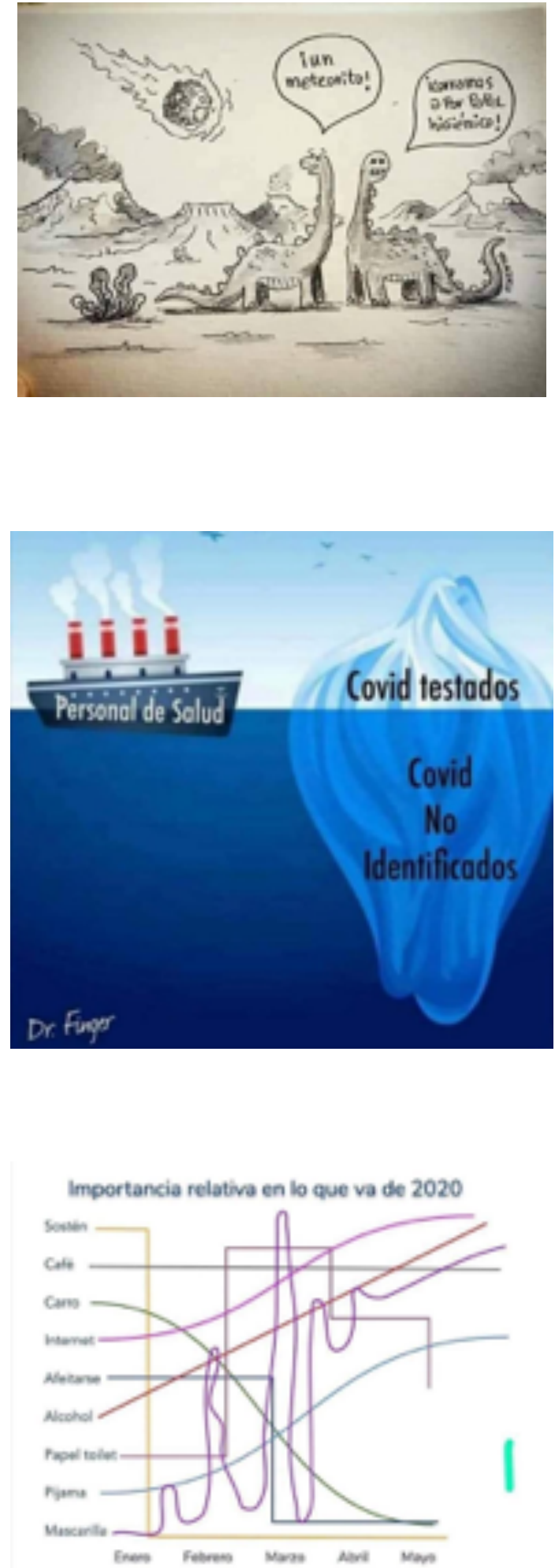

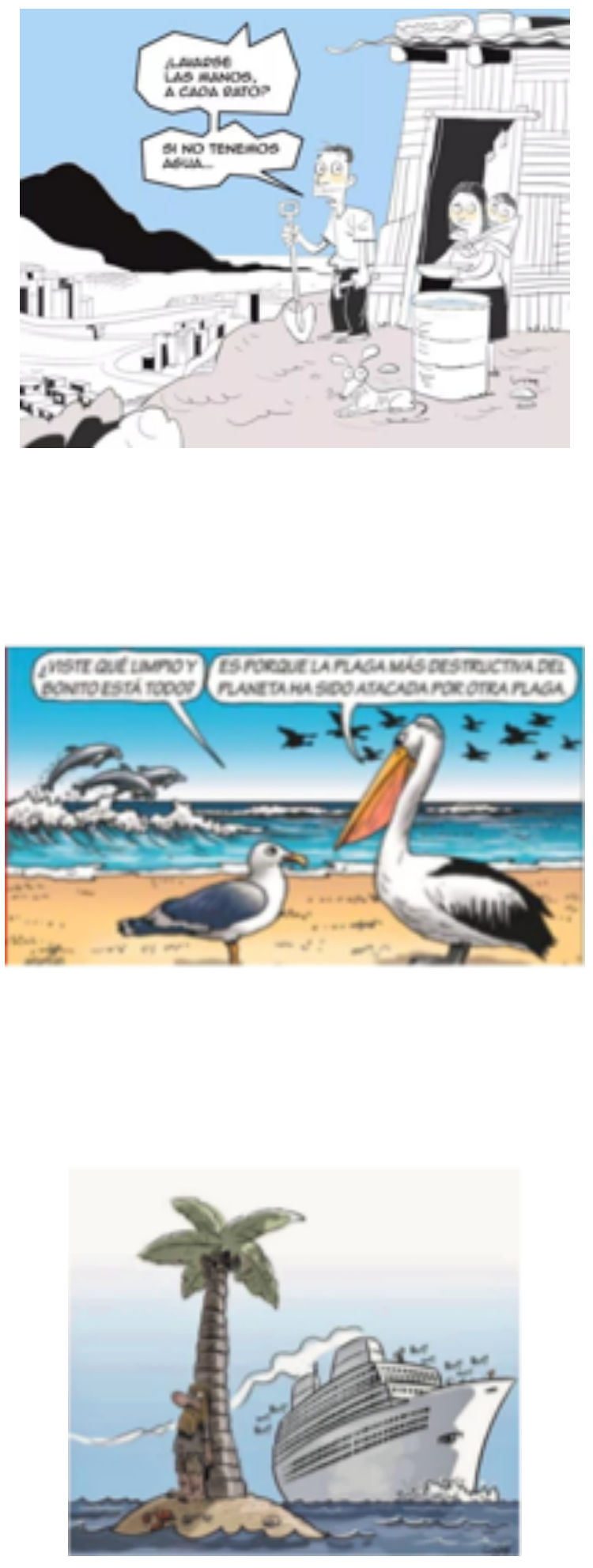
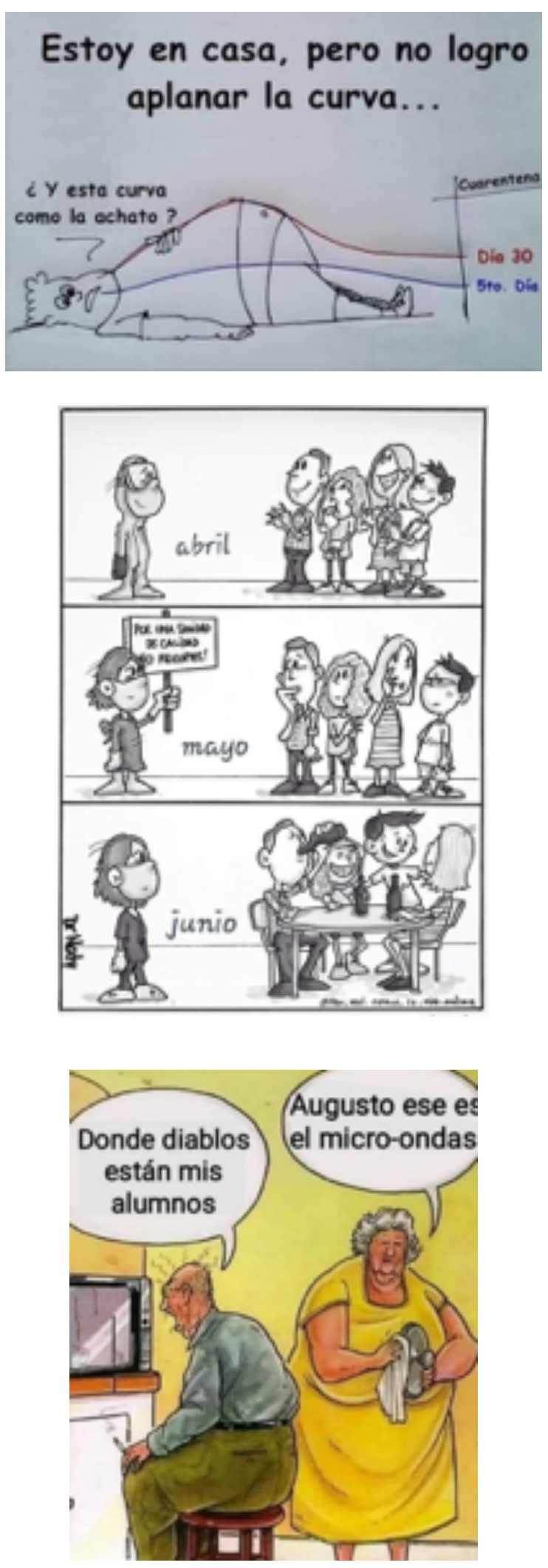
Con tanto panico hasta a mí me da miedo

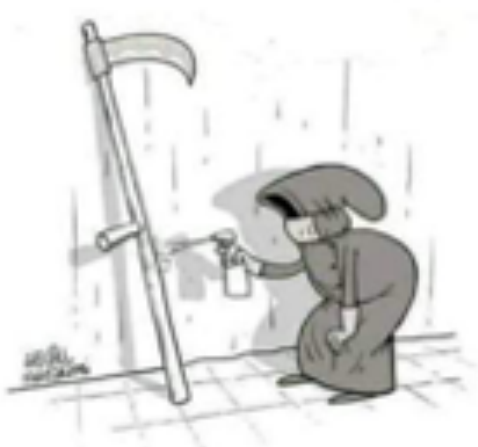

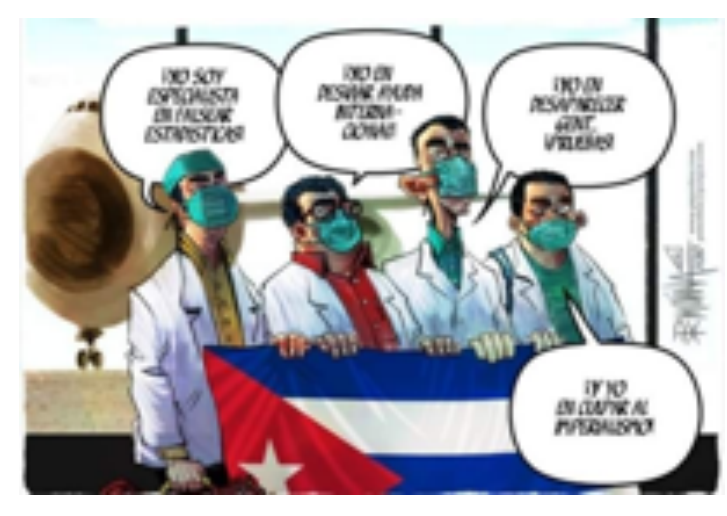

¿QUÉ LE DA A LA GENTE SENSACIÓN DE PODER?

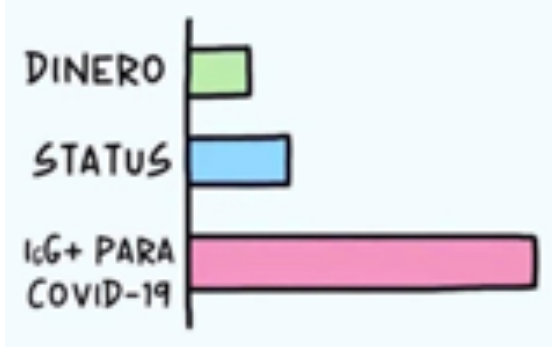

WHO LED THE DIGITLL TRANSFORAATION OF YOUR COMPANY ?

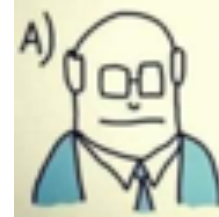

THE CEO
B)

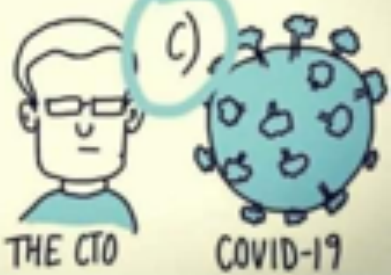

Hodthers

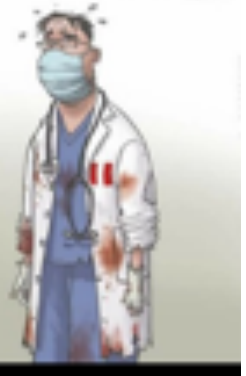

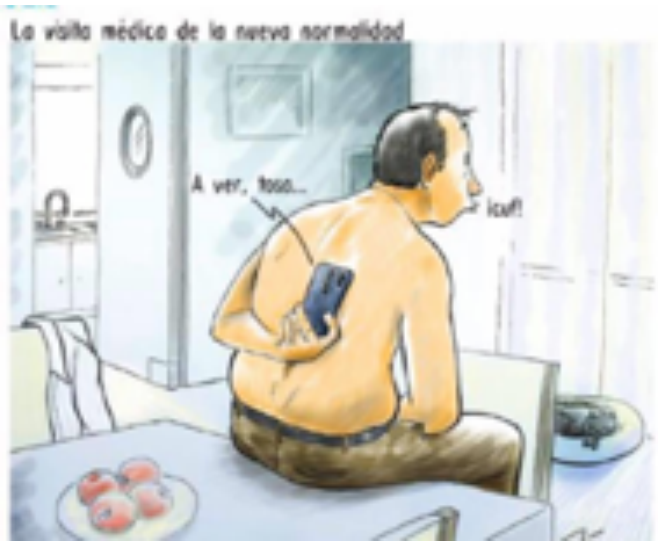



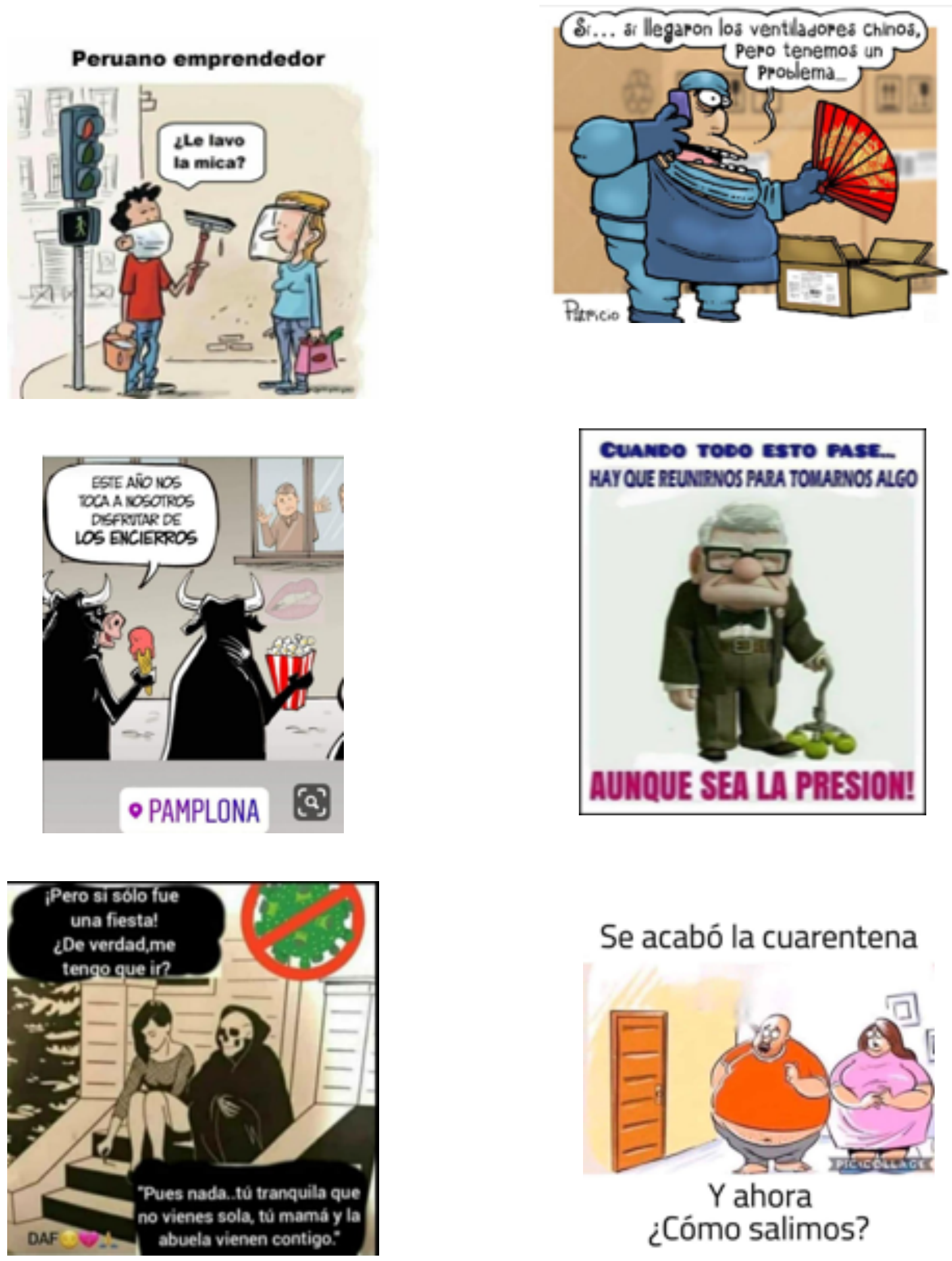

\section{Se acabó la cuarentena}

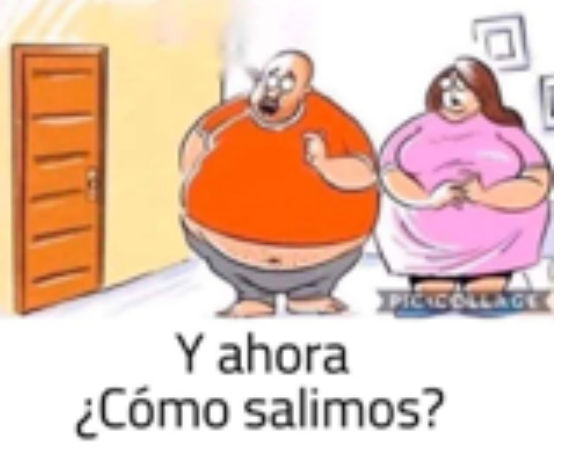



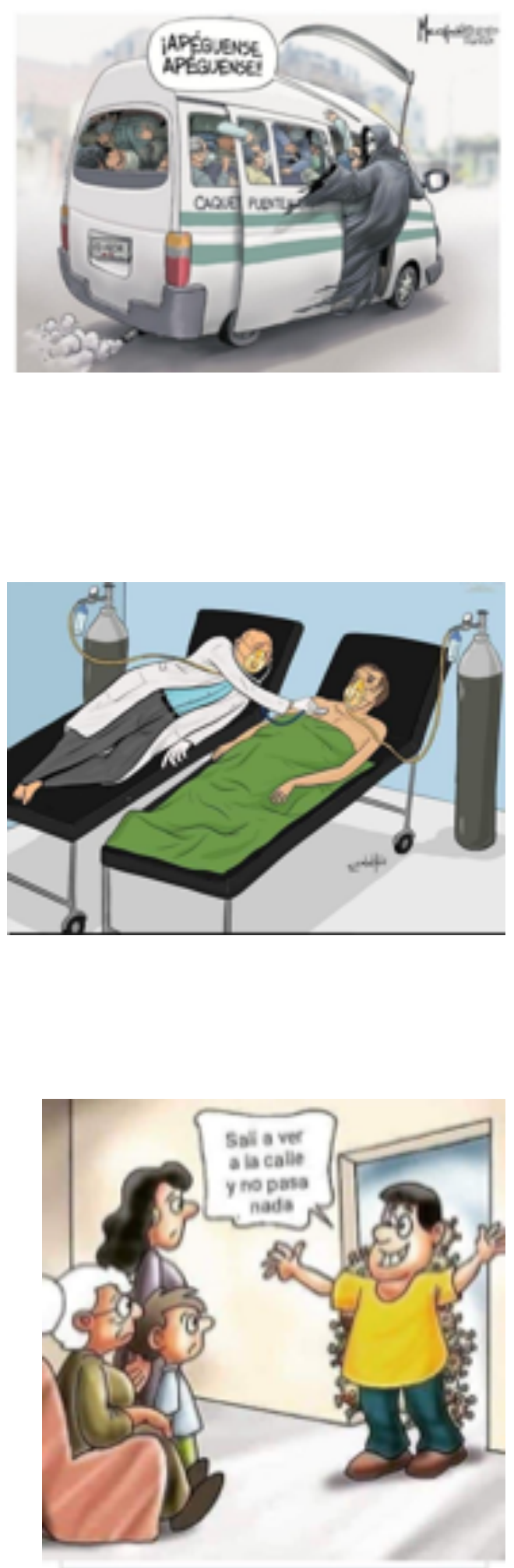
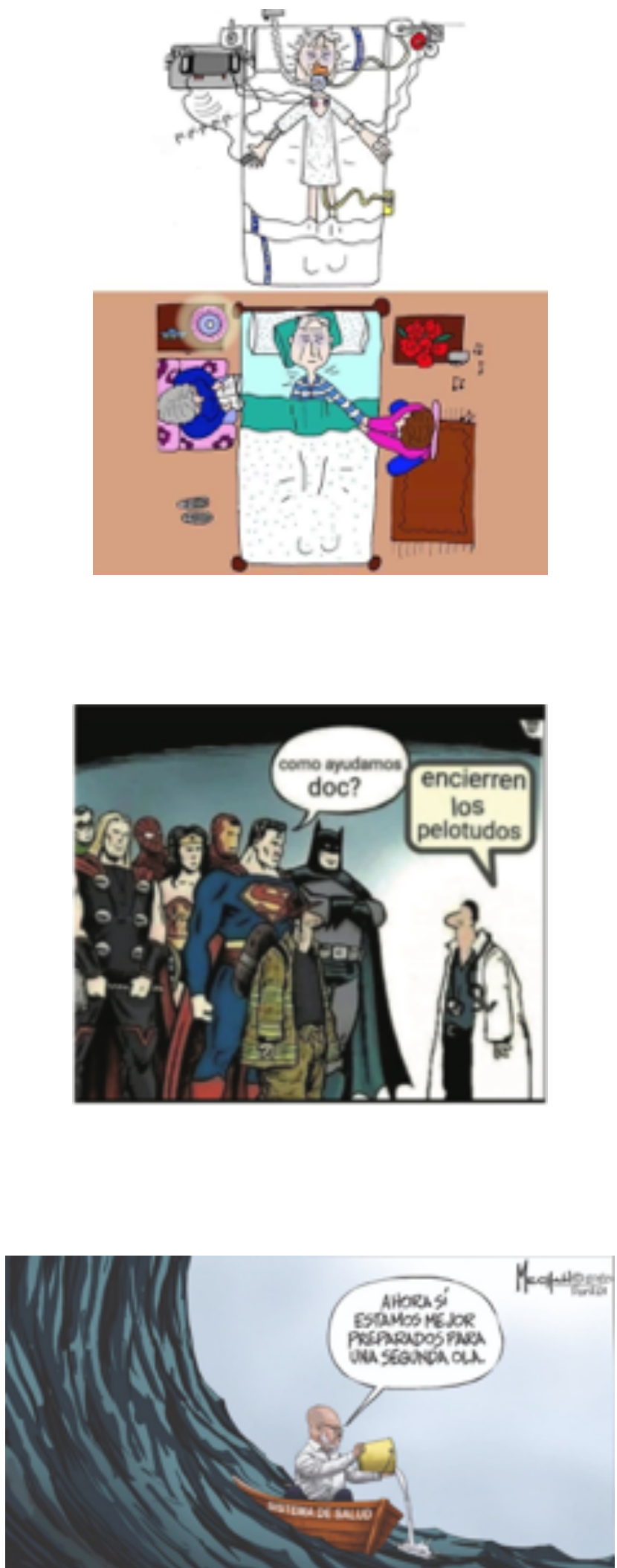

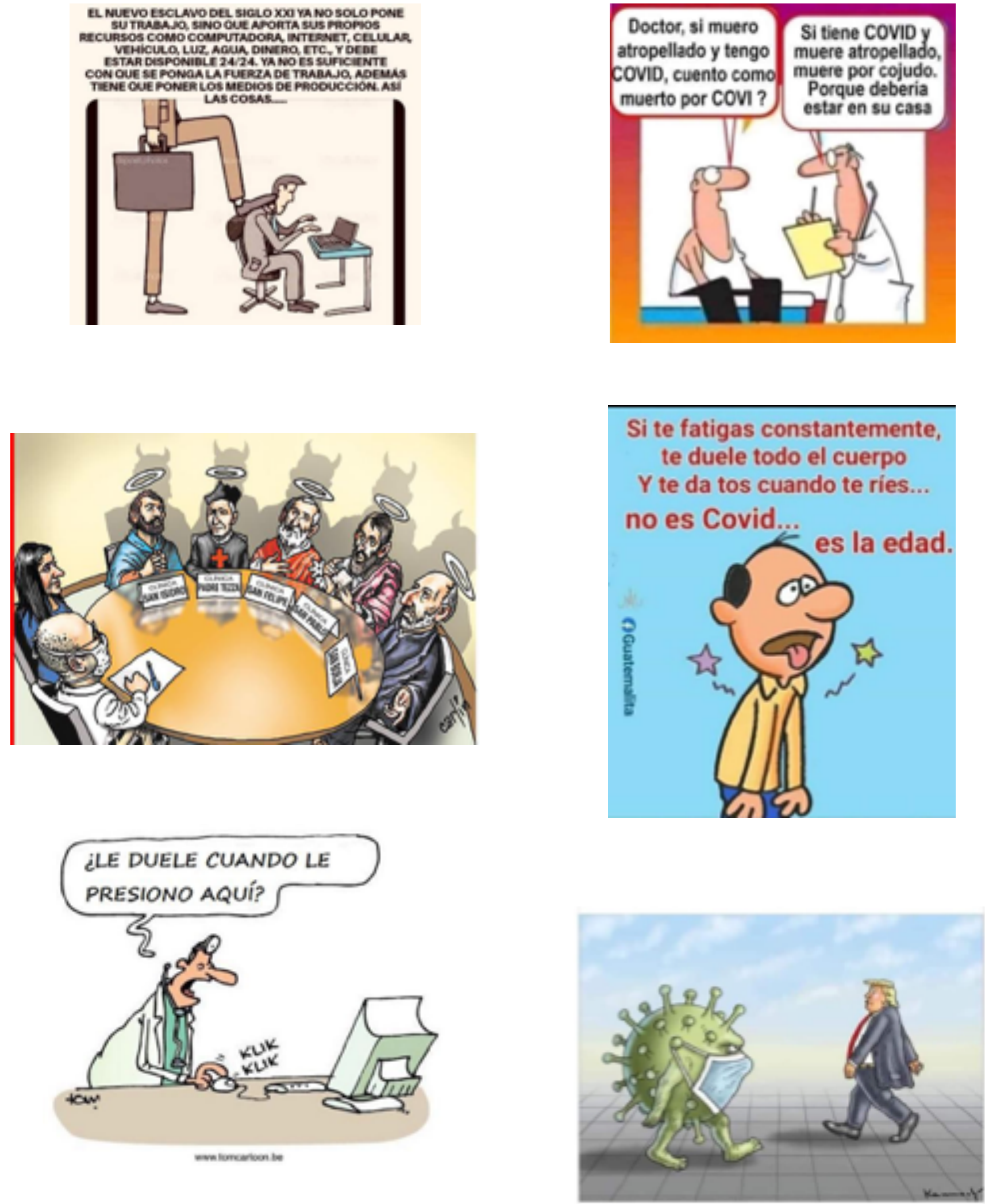

Acta Herediana vol. 64, N², julio 2021 - diciembre 2021 

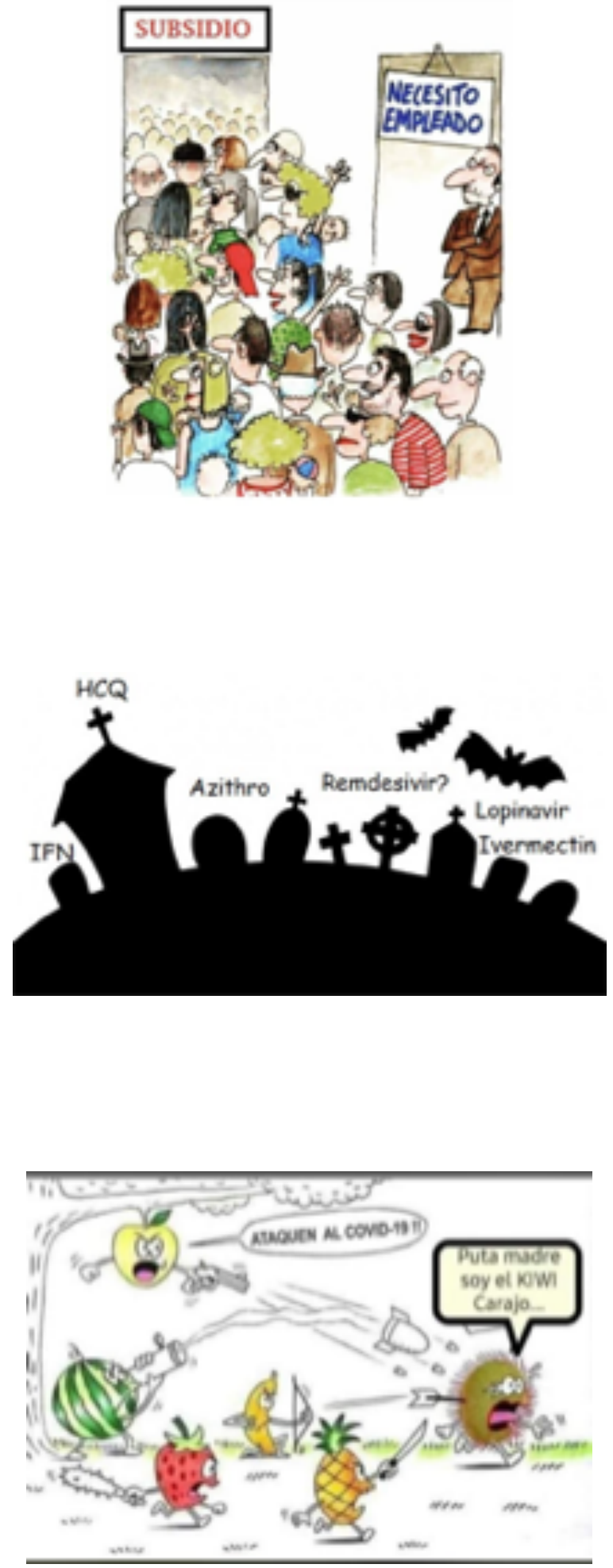
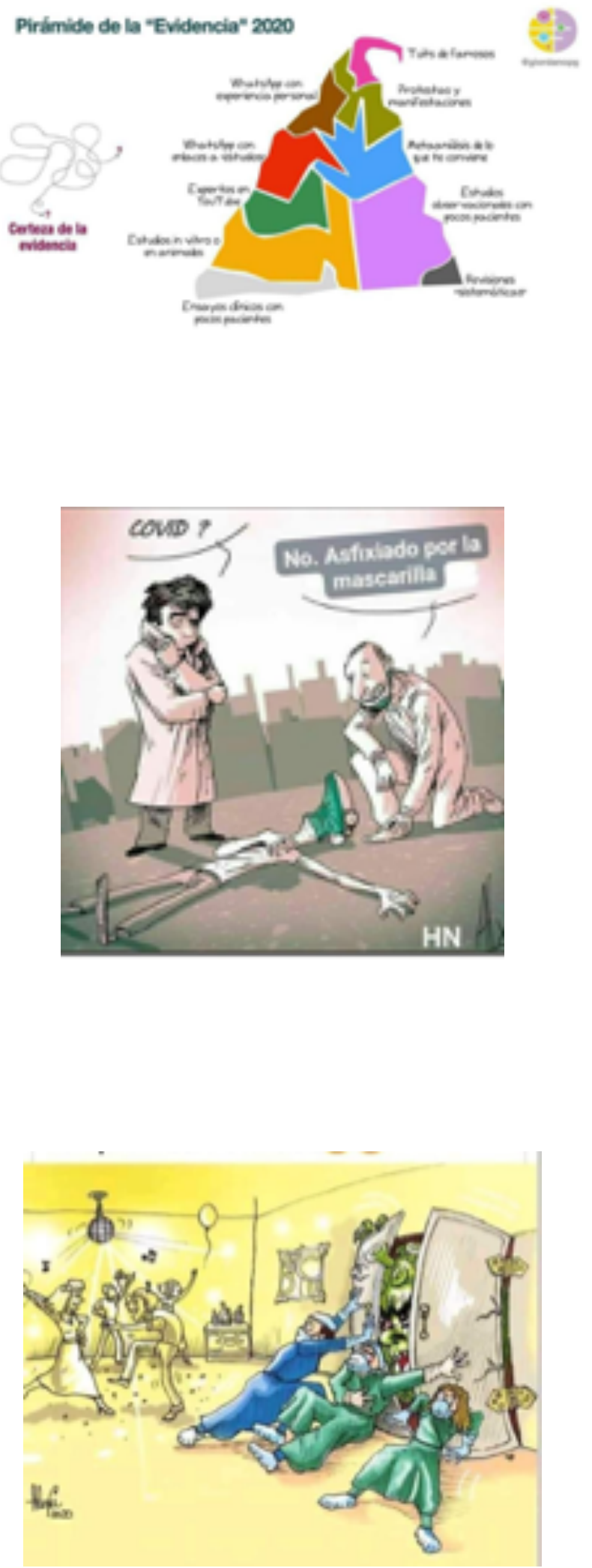

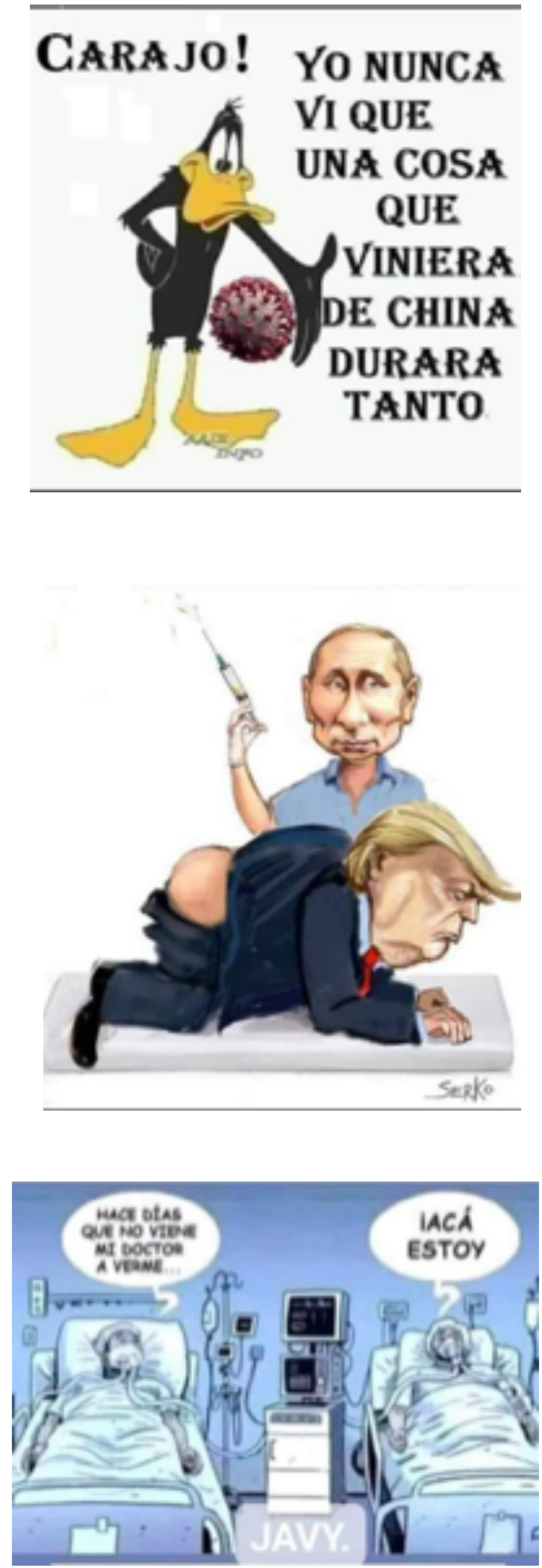
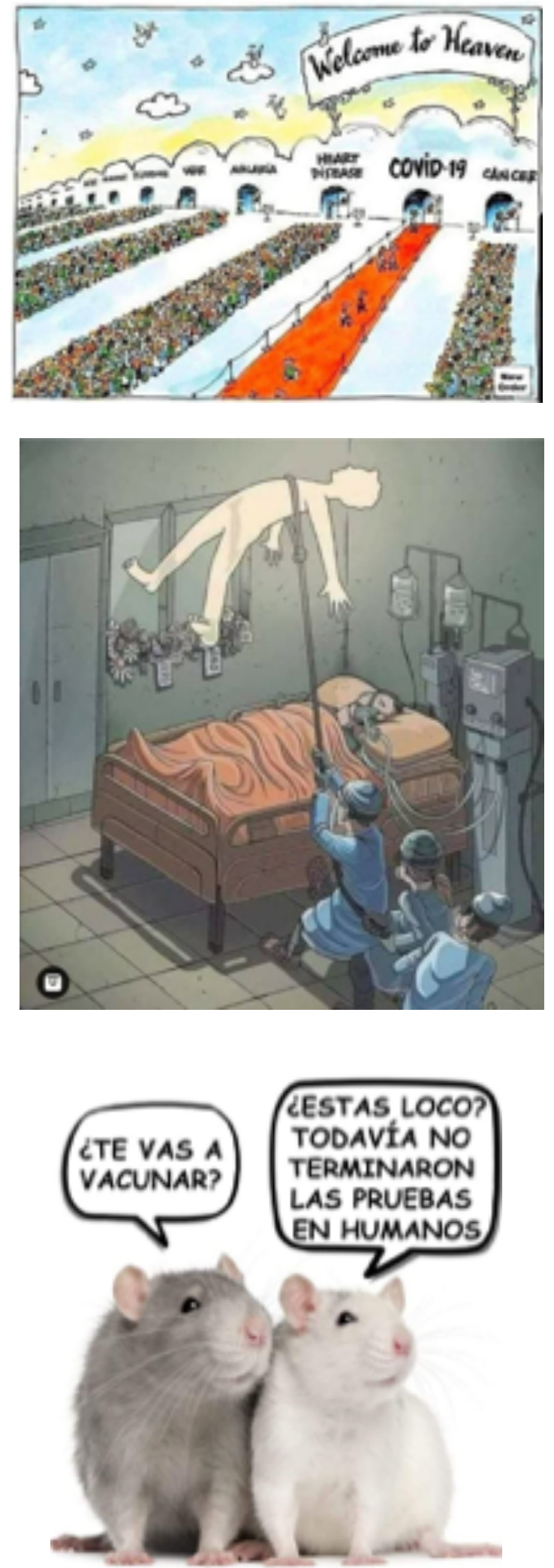


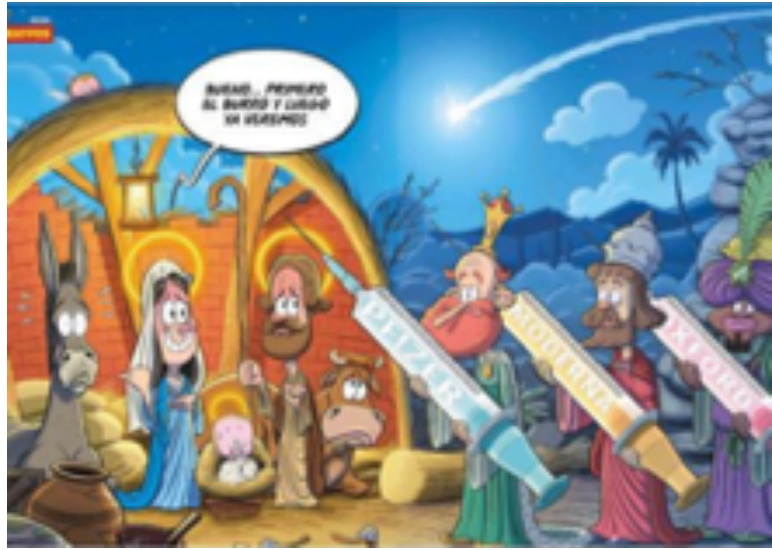

Y) IPUFFI, QUE NO ME PASE COMO EL AÑO PASADO, QUE INSTALE EL 2020, Y SE ME OLVIDO ACTIVAR EL ANTIVTRUS
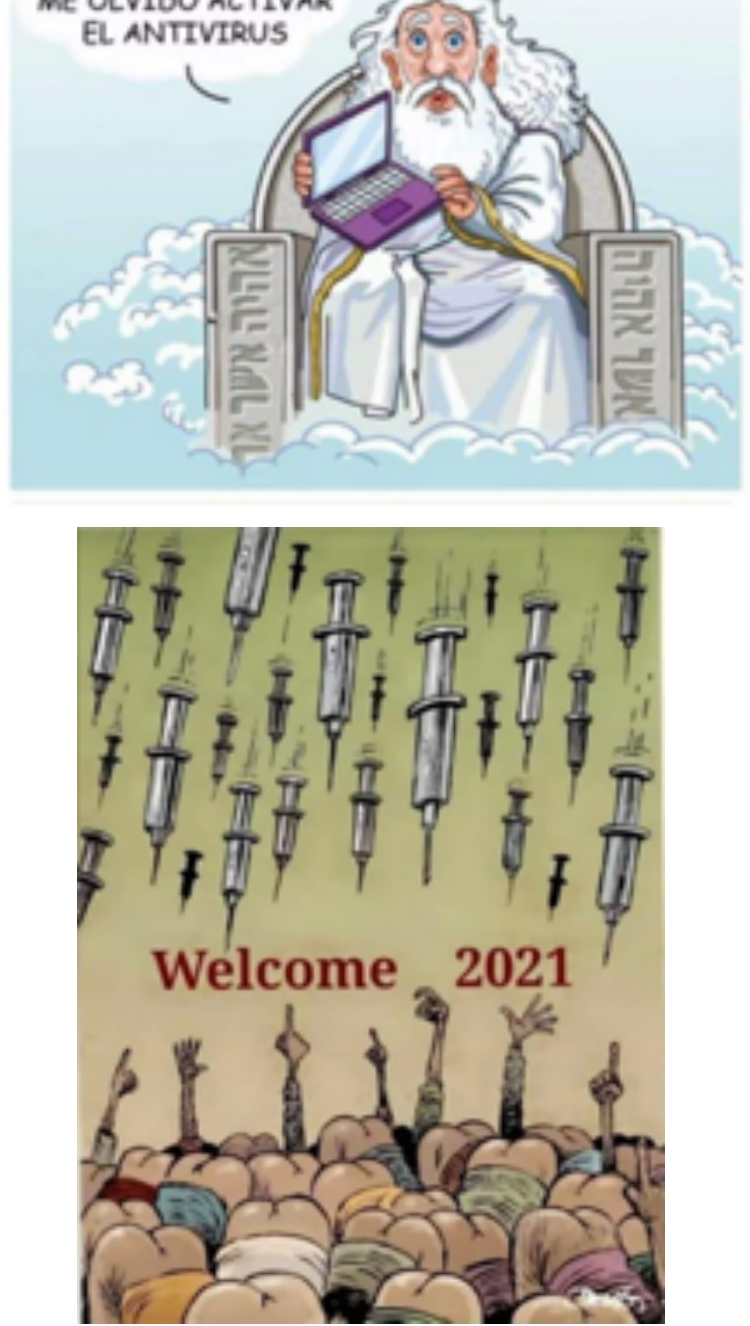
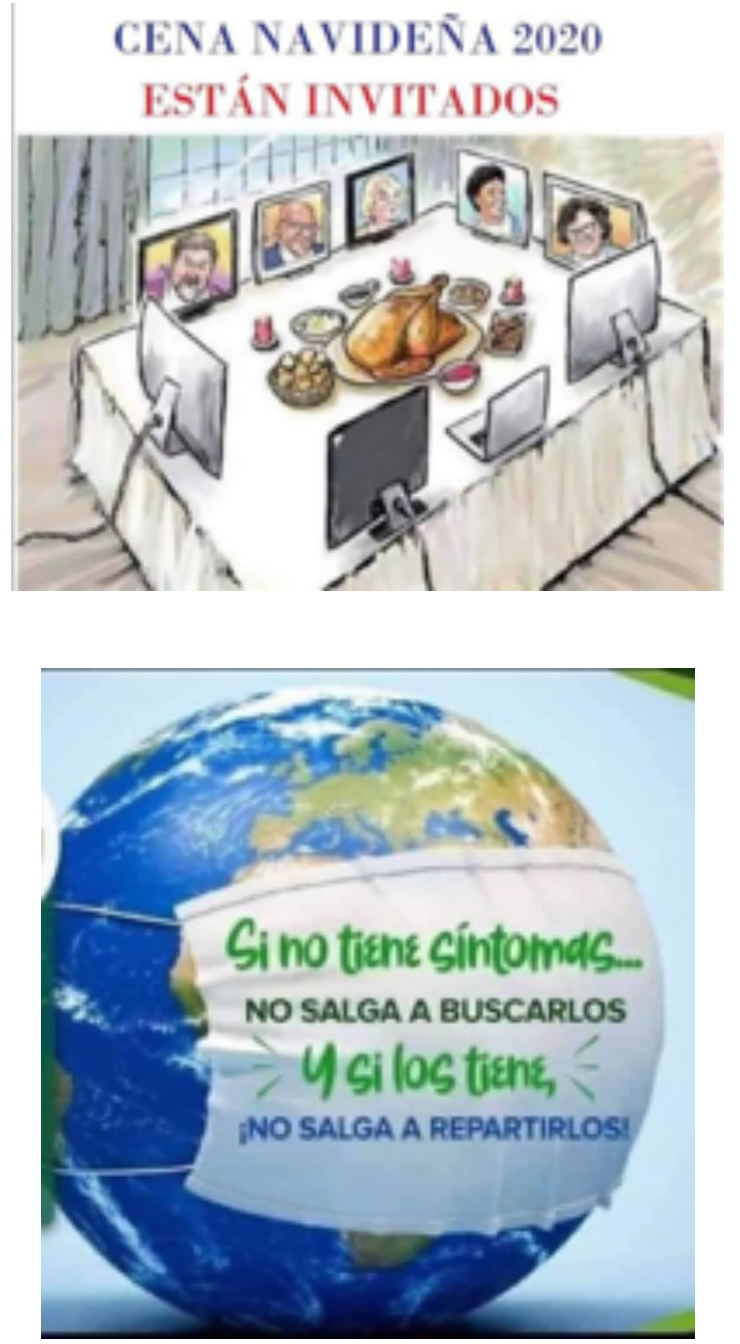

Esta va dedicada a toda esa gente que no creía en mí cuando apenas estaba empezando

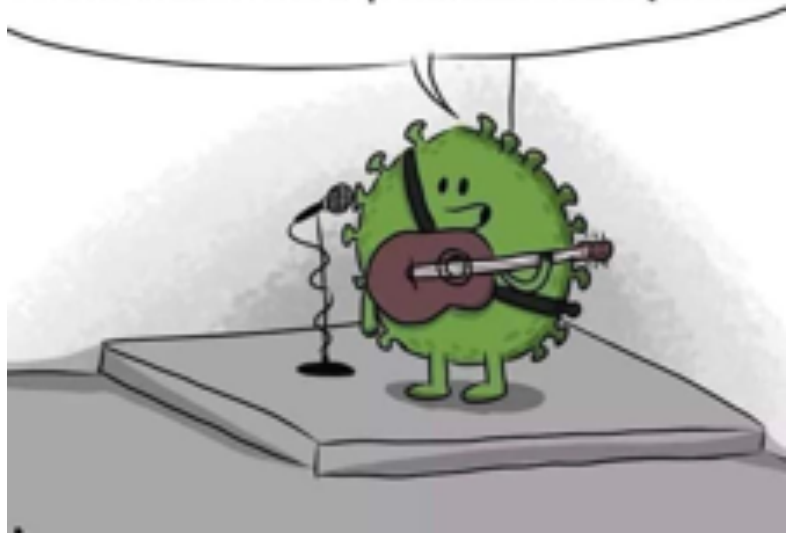



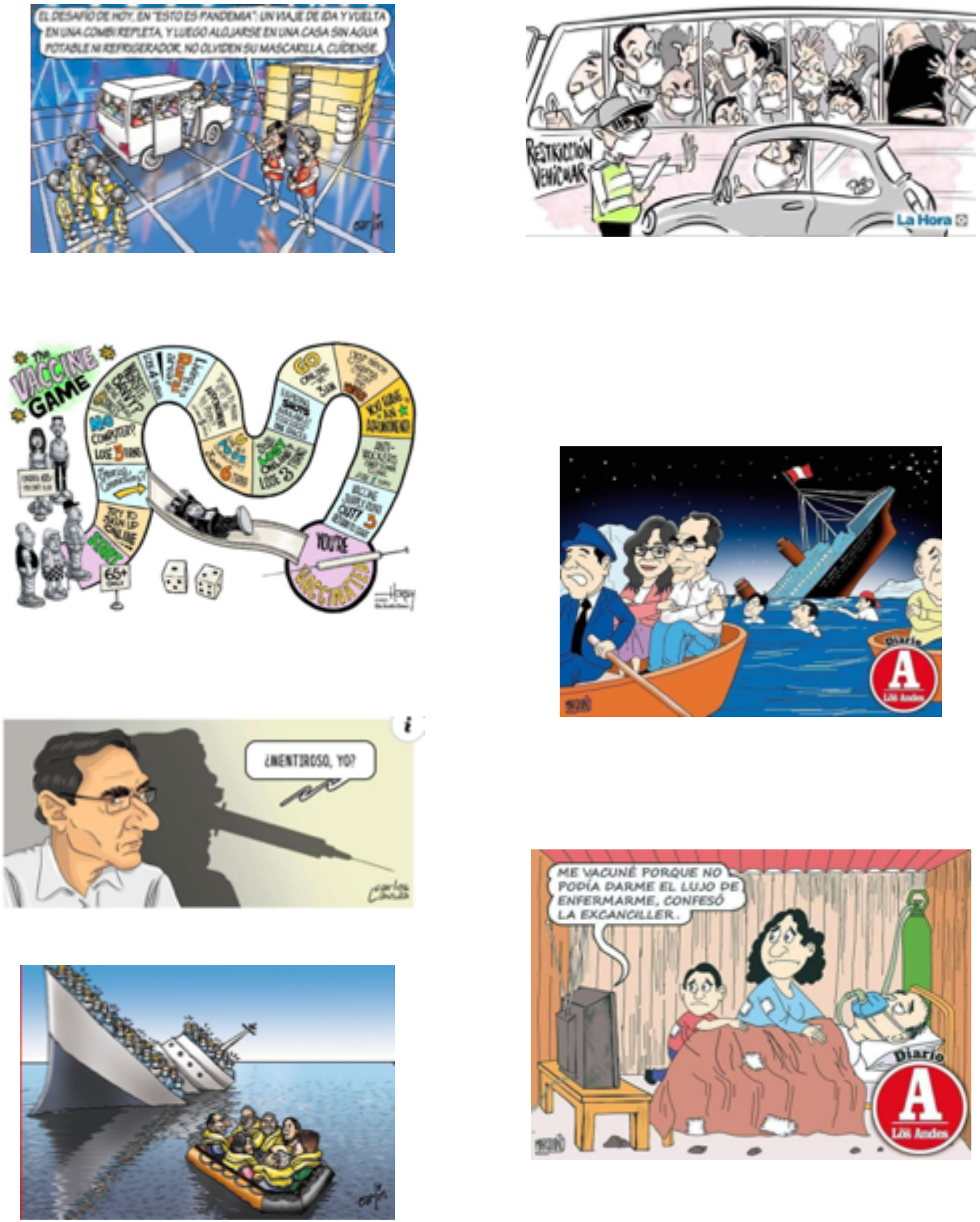
¿ALGUNA SABE CUANDO

ALCANZAMOS LA INMUNIDAD

LE REBAÑO?
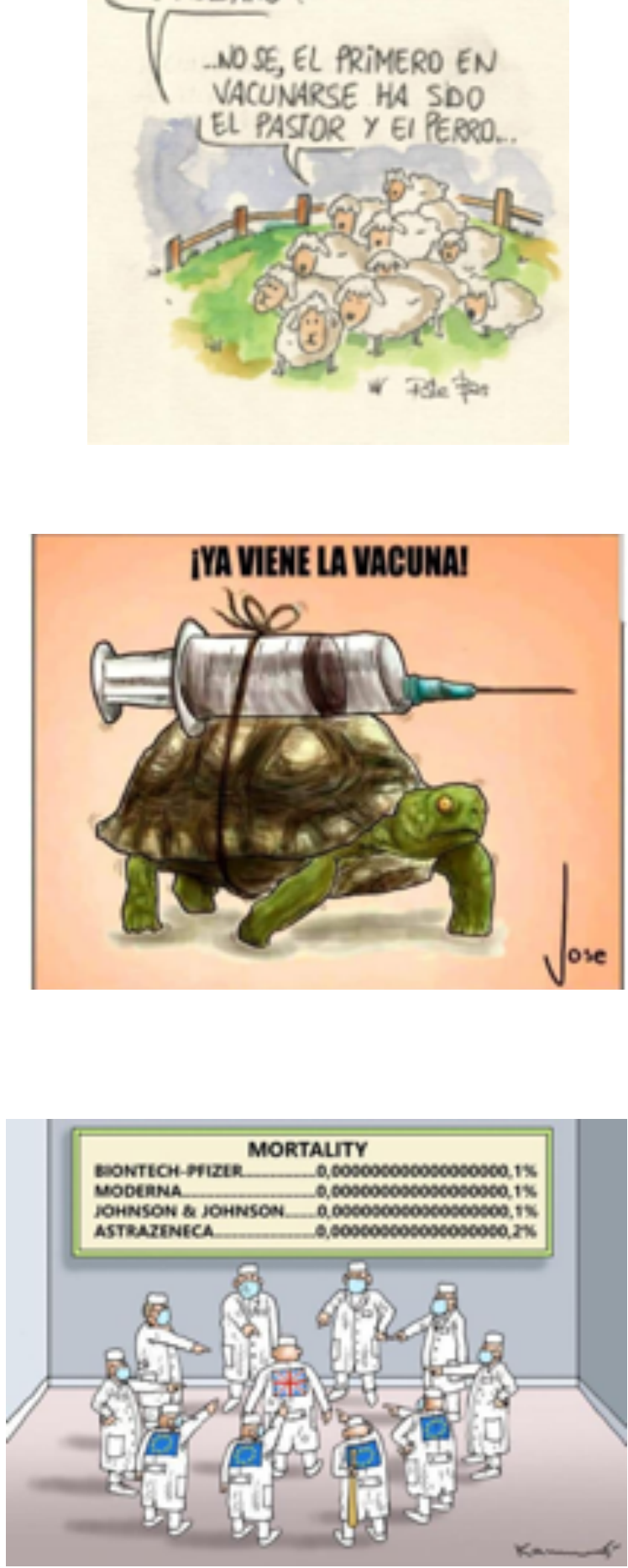
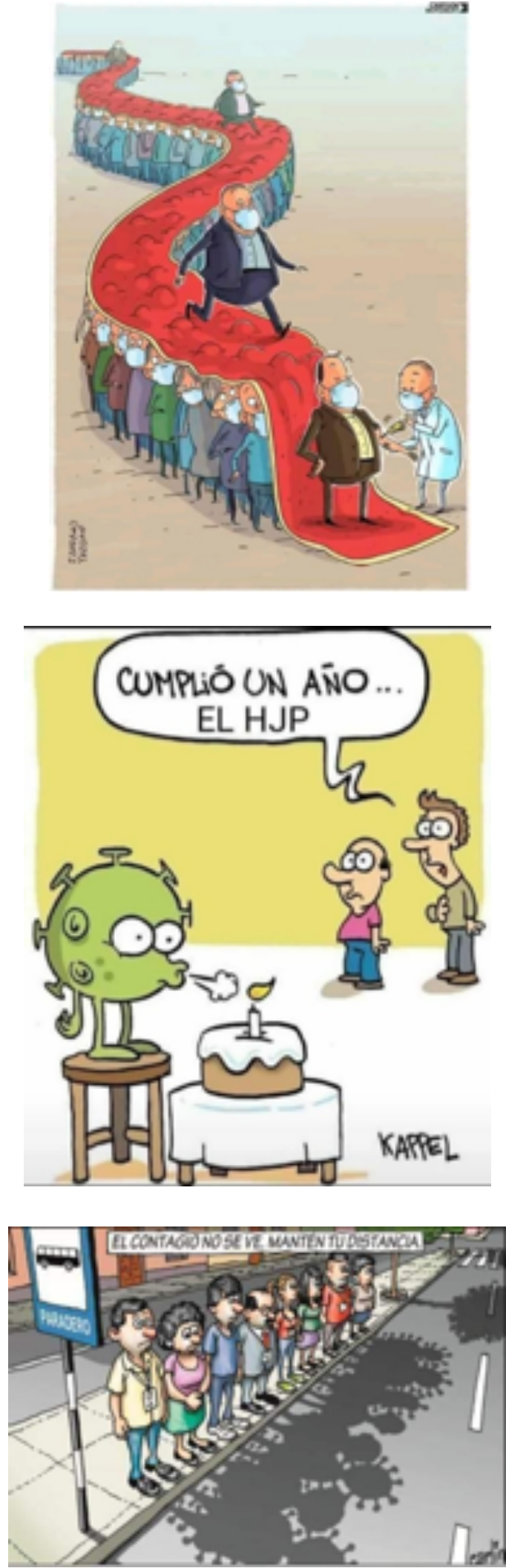

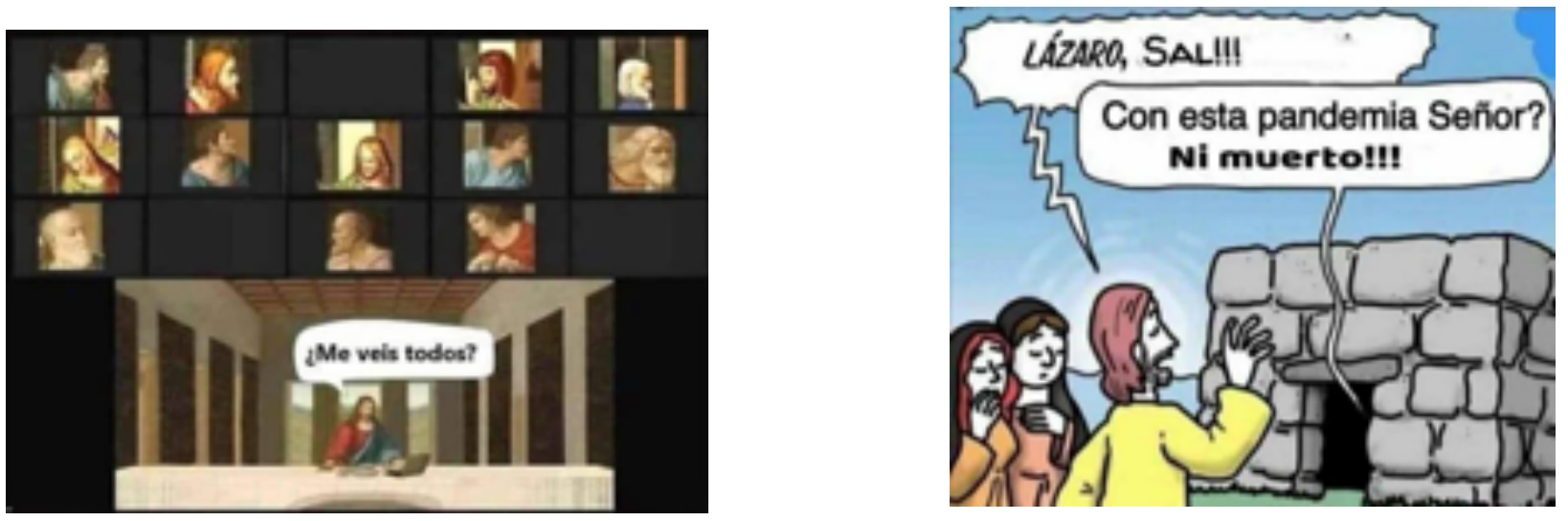

Teletrabajo femenino
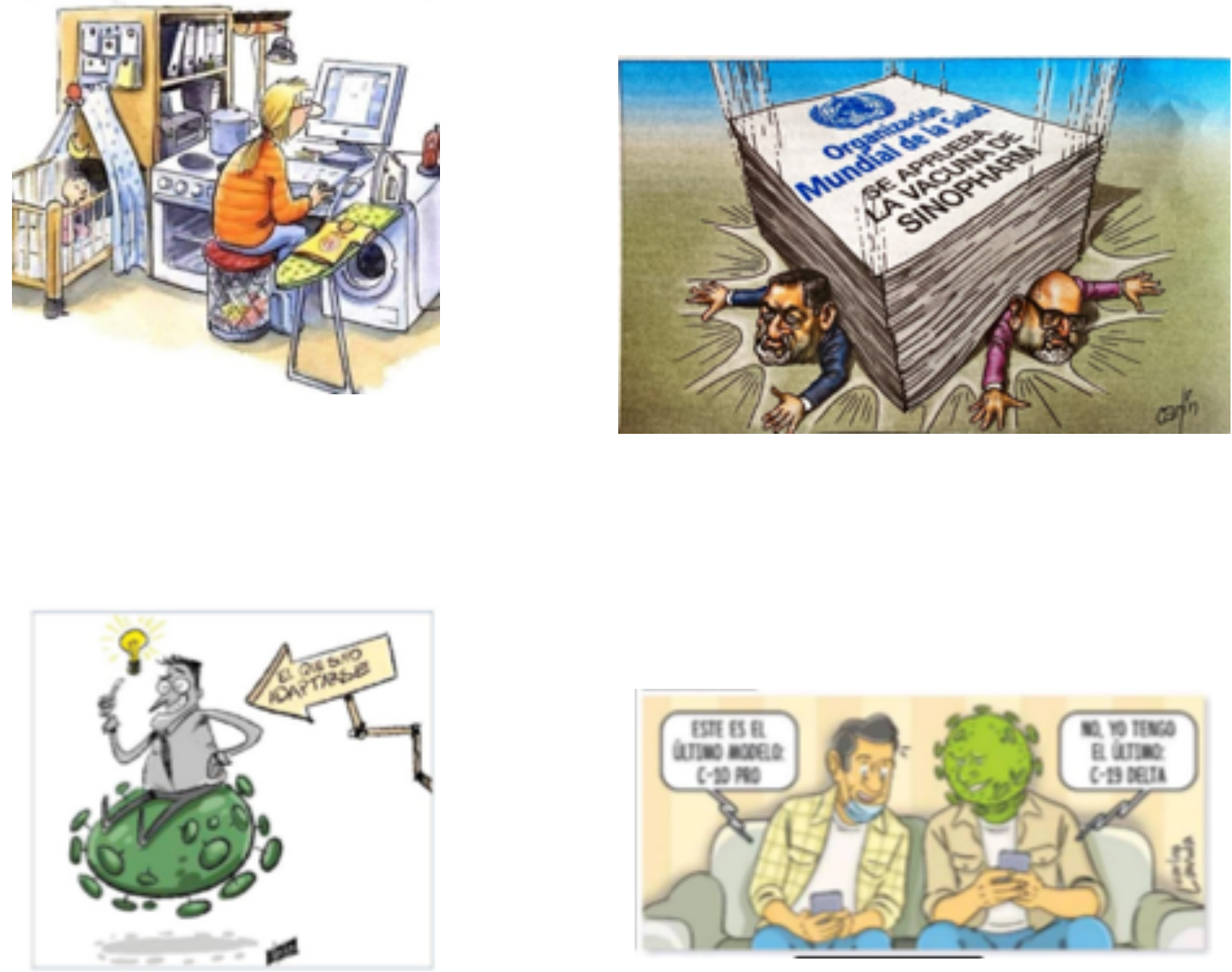

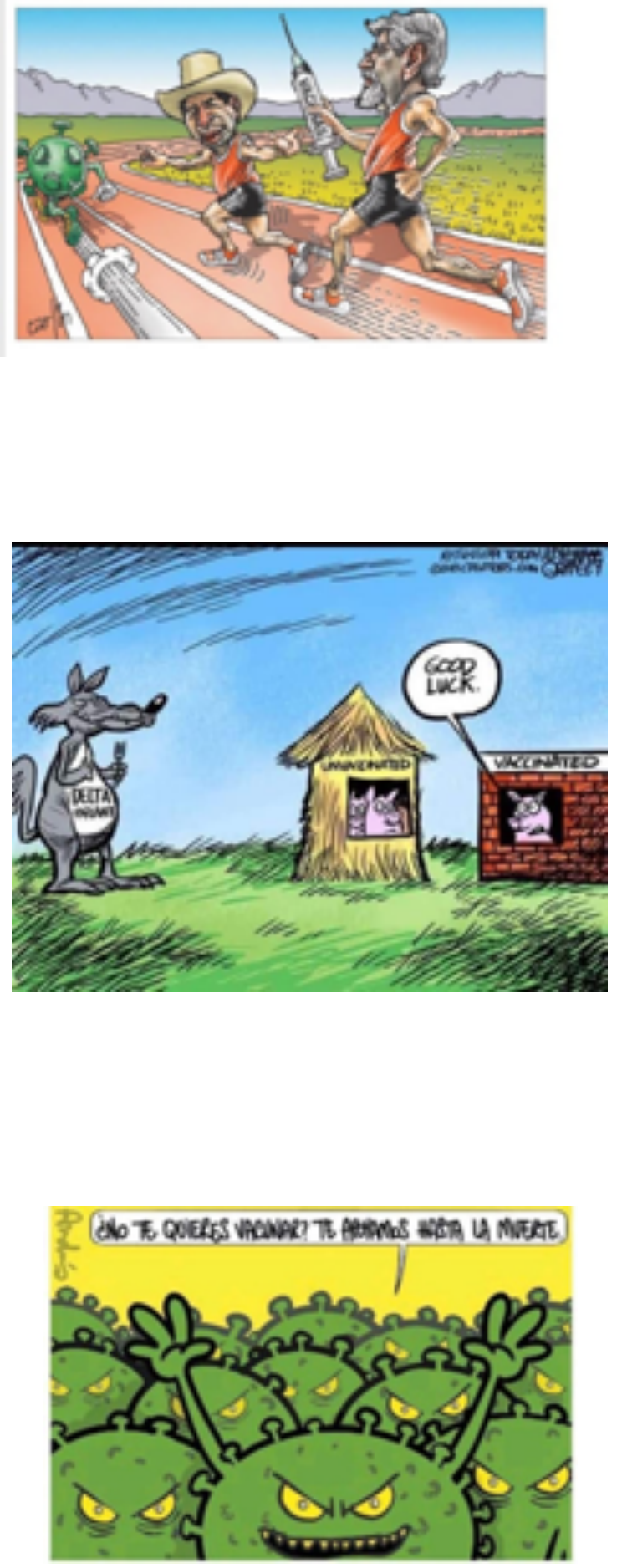

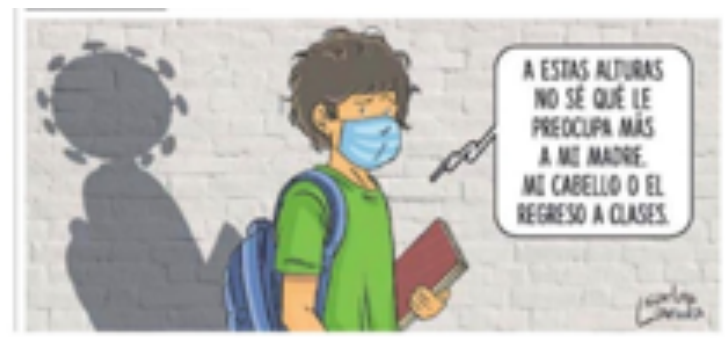

Cuando me pecguasias sobe la marea de las vacuess contra COVID

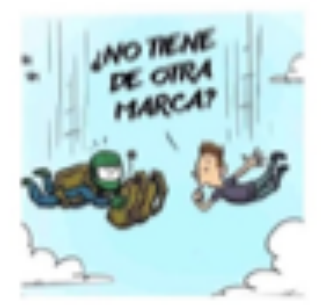

\#L.a mejer vacuna es la primera qque llega a mi hembro!:

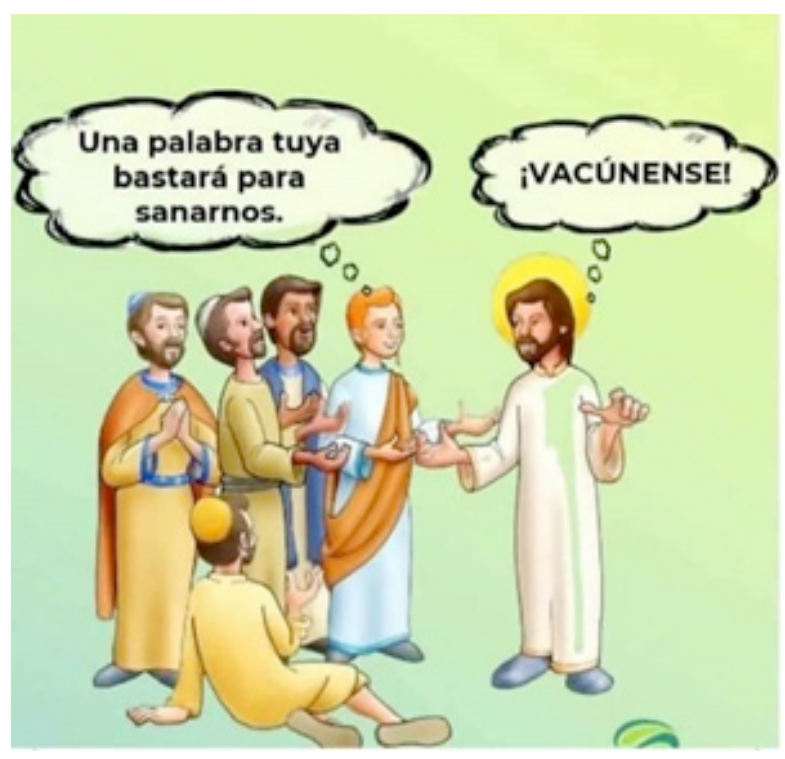

\section{Correspondencia:}

Oscar G. Pamo-Reyna

oscar.pamo@upch.pe

Fecha de recepción: 20-06-2021.

Fecha de aceptación: 20-08-2021.

Conflicto de interés: ninguno, según el autor.

Financiamiento: por el autor. 